\title{
Understanding the Physicochemical Characteristics and the Improved Enzymatic Saccharification of Corn Stover Pretreated with Aqueous and Gaseous Ammonia
}

\author{
Chang Geun Yoo ${ }^{1}$ Hoon $\mathrm{Kim}^{2} \cdot$ Fachuang $\mathrm{Lu}^{2}$ - Ali Azarpira ${ }^{2}$ Xuejun Pan $^{1}$. \\ Kyeong Keun $\mathrm{Oh}^{3}$ • Jun Seok Kim ${ }^{4}$ • John Ralph ${ }^{1,2}$ - Tae Hyun Kim ${ }^{5}$
}

Published online: 16 August 2015

(C) Springer Science+Business Media New York 2015

\begin{abstract}
Physicochemical characteristics of corn stover pretreated by soaking in aqueous ammonia (SAA) and lowmoisture anhydrous ammonia (LMAA) were compared and investigated. The glucan digestibility of the treated biomass reached $90 \%$ (SAA) and $84 \%$ (LMAA). The LMAA pretreatment enhanced the digestibility by cleaving crosslinkages between cell wall components, whereas the SAA pretreatment additionally improved the digestibility by efficiently removing a major portion of the lignin under mild reaction conditions without significant loss of carbohydrates. Fourier transform infrared spectroscopy (FTIR), nuclear magnetic resonance (NMR), and gel permeation chromatography (GPC) revealed the structural and chemical transformations of lignin during the pretreatments. Both pretreatments effectively cleaved ferulate cell wall cross-linking that is associated with the recalcitrance of grass lignocellulosics toward enzymatic saccharification. Extracted lignin from SAA pretreatment was extensively depolymerized but retained "native" character, as evidenced by the retention of $\beta$-ether linkages.
\end{abstract}

Tae Hyun Kim

thkim@kongju.ac.kr; hitaehyun@gmail.com

1 Department of Biological Systems Engineering, University of Wisconsin, Madison, WI 53706, USA

2 Department of Biochemistry and the US DOE Great Lakes Bioenergy Research Center, Wisconsin Energy Institute, University of Wisconsin, Madison, WI 53726, USA

3 Department of Applied Chemical Engineering, Dankook University, Cheonan 330-714, Chungnam, Republic of Korea

4 Department of Chemical Engineering, Kyonggi University, Suwon 443-760, Gyonggi-do, Republic of Korea

5 Department of Environmental Engineering, Kongju National University, Cheonan 330-717, Chungnam, Republic of Korea
Keywords Ammonia-extracted lignin · Soaking in aqueous ammonia (SAA) $\cdot$ Low-moisture anhydrous ammonia $($ LMAA) $\cdot$ 2D NMR $\cdot$ FT-IR $\cdot$ Lignocellulosic material

\section{Introduction}

Among the various renewable energy resources that can provide alternatives to fossil fuels, liquid biofuels derived from lignocellulosic biomass show considerable potential for the transportation sector. Cellulosic ethanol, produced from lignocellulosic biomass materials that are indigestible and essentially non-edible by humans, is a transportation fuel already in use [1]. However, commercialization of cellulosic ethanol production remains challenging because of technical and economic barriers $[2,3]$. In plants, lignin provides a crucial defense system against pathogens; however, it also represents an obstructive component to the bioconversion of biomass into ethanol. Cellulose crystallinity, and non-crystalline components including lignin and hemicelluloses, along with their various acyl (acetyl, feruloyl, and $p$-coumaroyl) group decorations, all contribute to poor enzymatic hydrolysability of natural lignocellulosic biomass $[4,5]$.

Efficient technologies to overcome the biomass recalcitrance are crucial for commercialization of cellulosic ethanol. Numerous pretreatment methods have been developed to improve the saccharification of biomass to sugars and their subsequent fermentation to ethanol and other biofuels. Ammonia has been introduced as a reagent for biomass pretreatment because of its high selectivity toward lignin and cell wall cross-linking entities over polysaccharides, its swelling effect on cell wall, its high volatility for easy recovery and reuse, and its ability to reduce cellulose crystallinity [6-8]. Ammonia's antibacterial properties allow long-term storage of pretreated biomass with minimal carbohydrate degradation [9], and the retained ammonia- 
derived nitrogen can serve as a nutrient in the subsequent fermentation process [10]. Different pretreatment methods using ammonia, including ammonia fiber expansion (AFEX), soaking in aqueous ammonia (SAA), ammonia recycle percolation (ARP), and low-moisture anhydrous ammonia (LMAA), have been investigated for enhancing the enzymatic hydrolysis and fermentation of biomass $[6-8,11,12]$.

In this study, two recently developed ammonia pretreatments, SAA and LMAA, were conducted to pretreat corn stover. The SAA uses aqueous ammonia ("ammonium hydroxide") under mild reaction conditions $\left(30-80{ }^{\circ} \mathrm{C}, 1-\right.$ $2 \mathrm{~atm}$ ) in a batch process to remove lignin without significant loss of sugars. Delignification not only improves the enzymatic hydrolysis but also enriches carbohydrates in the pretreated solid substrate. The LMAA, unlike most other pretreatments that involve liquid chemicals or solutions, uses gaseous ammonia to pretreat biomass, which significantly reduces ammonia loading and water consumption [11]. For recovery of ammonia, it is projected that simple evaporation should be used in both SAA and LMAA. It is also assumed that ammonia recovery in LMAA is simpler due to its low ammonia and water loadings than SAA. In addition, ammonia distribution via the gaseous phase is easier, and water washing of the pretreated biomass is not necessary before enzymatic hydrolysis and fermentation. In the ammoniation reactor, ammonia gas rapidly penetrates into moist biomass, and the pretreatment is completed under relatively mild temperatures $(60$ $90^{\circ} \mathrm{C}$ ). Instead of removing components inhibitory to cellulose hydrolytic enzymes, such as lignin and/or hemicellulose from biomass, the LMAA pretreatment removes/reduces biomass recalcitrance and improves cellulose digestibility by changing the structures of biomass components [11].

The effects of the SAA and the LMAA pretreatments on the physicochemical structural aspects of corn stover and the enzymatic digestibility were investigated. Chemical composition and functional groups in the untreated and pretreated biomass samples were analyzed by wet chemistry methods and FTIR analysis. Lignin structure before and after the pretreatment was compared by the 2D-NMR (HSQC) method. Ammonia-extracted lignin from SAA pretreatment was characterized in terms of purity, structure, and molecular weight. The effects of the two pretreatments on glucan and xylan digestibilities were also investigated. The findings reported in this study will help in understanding ammonia process options for the effective pretreatment of lignocellulosic biomass.

\section{Materials and Methods}

\section{Materials}

Corn stover was harvested from central Iowa in 2010. For uniform reaction, corn stover was ground, and the fraction between 10 and 30 mesh was used in this study. The corn stover contained $35.3 \%$ glucan, $23.9 \%$ xylan, $1.9 \%$ galactan, $4.0 \%$ arabinan, $19.9 \%$ lignin (acid insoluble + acid soluble), $4.1 \%$ ash, and $10.9 \%$ water-ethanol extractives.

Cellulase (GC 220, Lot \#301-04232-162, 45 FPU (filter paper unit) $/ \mathrm{mL}$ ) and xylanase (Multifect ${ }^{\circledR}$, Lot \#301-04021015, $8000 \mathrm{GXU}$ (Genencor xylanase unit)/mL, $42 \mathrm{mg}$ of protein $/ \mathrm{mL}$ ) were provided by Genencor International. $\beta$ Glucosidase (Novozyme 188, Lot \#11 K1088, 750 CBU (cellobiose unit) $/ \mathrm{mL}$ ) was purchased from Sigma-Aldrich (St. Louis, MO, USA).

\section{Pretreatments}

\section{Low-Moisture Anhydrous Ammonia}

The ammoniation reactor system consists of a batch reactor $(7.2 \times 16.5 \mathrm{~cm}$, internal diameter $\times$ length $)$ with an internal volume of $670 \mathrm{~mL}$, a single-stage gas regulator (Linweld 313 stainless steel, Linweld Inc., Des Moines, IA, USA), and an ammonia gas cylinder. Before starting the ammoniation, the reactor was purged using ammonia gas for $10 \mathrm{~s}$. Corn stover with $50 \%$ moisture content was loaded into the reactor and treated with anhydrous ammonia gas for $10 \mathrm{~min}$. During the ammoniation, the system pressure was about $10 \mathrm{psi}$ and temperature and pressure were monitored by an electronic temperature probe and pressure gauge. The exothermic reaction of ammonia with moisture in the biomass increased temperatures up to $70{ }^{\circ} \mathrm{C}$ without external heating. Ammoniated biomass was transferred into a stainless steel reactor $(2.4 \times 15.2 \mathrm{~cm}$, internal diameter $\times$ length $)$ with an internal volume of $67 \mathrm{~mL}$ and kept at $80{ }^{\circ} \mathrm{C}$ for $1-84 \mathrm{~h}$. After all the reactions, ammonia from the treated biomass was allowed to evaporate in a fume hood. The pretreated samples were subjected to the compositional analysis and enzymatic digestibility test following the National Renewable Energy Laboratory (NREL) Laboratory Analytical Procedure (LAP) [13].

\section{Soaking in Aqueous Ammonia Pretreatment}

For the SAA pretreatment, $100 \mathrm{~mL}$ of $15 \%$ of ammonium hydroxide was loaded into a screw-capped Pyrex bottle with $10 \mathrm{~g}$ (oven-dried weight) of corn stover. The bottle was placed in a convection oven at $60{ }^{\circ} \mathrm{C}$ for 3-24 h. At the end of the treatment, the treated solids were separated by filtration, washed with deionized (DI) water until the eluent's $\mathrm{pH}$ reached 7-8, and subjected to the enzymatic digestibility test. Lignin, carbohydrate, and enzymatic digestibility were determined and evaluated by the NREL-LAP. 


\section{Enzymatic Digestibility Test}

To evaluate the effect of each pretreatment on biomass conversion, the enzymatic digestibility of pretreated biomass was evaluated with GC-220 cellulase, Nov. $188 \beta$-glucosidase, and Multifect ${ }^{\circledR}$ xylanase. The initial glucan loading was $1 \%$ $(w / v)$ in $100 \mathrm{~mL}$ of total liquid and solid mixture. The substrate and enzymes were loaded into a 250-mL Erlenmeyer flask as a bioreactor and shaken in an incubating shaker (Model E24, New Brunswick Scientific, Edison, NJ, USA) at $50{ }^{\circ} \mathrm{C}$ and $150 \mathrm{rpm}$. The $\mathrm{pH}$ of each substrate was adjusted to $\mathrm{pH} 4.8$ with $0.05 \mathrm{M}$ sodium citrate buffer solution at the beginning of the enzymatic hydrolysis. Enzymes including $15 \mathrm{FPU} / \mathrm{g}$ glucan of the cellulase, $30 \mathrm{CBU} / \mathrm{g}$-glucan of the $\beta$-glucosidase, and $1000 \mathrm{GXU} / \mathrm{g}$-glucan of the xylanase were loaded for hydrolysis of polysaccharides in the substrate. Each substrate was tested in duplicate, and samples were taken and analyzed periodically until the hydrolysis tested as complete typically in 96-120 h. The glucan and xylan were analyzed using a high-performance liquid chromatography (HPLC).

The glucan and xylan digestibilities were calculated as:

Glucan $\left(\right.$ or xylan) digestibility $(\%)=\frac{\text { Total released glucose }(\text { or xylose })(\mathrm{g}) \times \text { conversion factor }}{\text { Initial glucan }(\text { or xylan }) \text { loaded }(\mathrm{g})} \times 100$

where the conversion factors for glucose and xylose to the equivalent glucan and xylan are 0.90 and 0.88 , respectively.

\section{Analytical Methods}

\section{Chemical Composition}

The chemical composition (carbohydrates and lignin) of untreated and pretreated samples were determined in duplicate according to the method of the NREL-LAP [13]. Carbohydrates were determined by HPLC (Varian ProStar 230, Varian Inc., CA, USA) with Aminex HPX-87P column (1300× $7.8 \mathrm{~mm}, 9 \mu \mathrm{m}$ particle size) (Bio-Rad Laboratories Inc., CA, USA) and a refractive index (RI) detector (Varian 356-LC, Varian Inc., CA, USA). Lignin fractions (AIL, acid-insoluble lignin and ASL, acid-soluble lignin) were quantitated by weight and spectroscopic analysis using UV spectrophotometer (Unico $2100 \mathrm{UV}, \mathrm{Unico}^{\circledR}, \mathrm{NJ}, \mathrm{USA}$ ) at $320 \mathrm{~nm}$, respectively.

\section{Fourier Transform Infrared Spectroscopy}

Functional groups in the solid substrates were analyzed by Fourier transform infrared spectroscopy (FTIR). The spectra were obtained on a Nicolet ${ }^{\mathrm{TM}} 380$ FTIR spectrometer working in attenuated total reflectance (FTIR-ATR) mode (Thermo Fisher Scientific Inc., Waltham, MA, USA). Samples were scanned from 4000 to $600 \mathrm{~cm}^{-1}$ at a resolution of $4 \mathrm{~cm}^{-1}$. The assignments of peaks in the FTIR spectra were summarized in Table 1 according to the previous studies [14-22].

\section{Nuclear Magnetic Resonance}

Samples of untreated and ammonia-treated corn stover were prepared for gel-state nuclear magnetic resonance (NMR) as previously described [23]. In brief, the dried sample was pre-ground for $1 \mathrm{~min}$ in a Retsch MM400 mixer mill at $30 \mathrm{~Hz}$ using zirconium dioxide $\left(\mathrm{ZrO}_{2}\right)$ vessels $(10 \mathrm{~mL})$ containing $\mathrm{ZrO}_{2}$ ball bearings $(2 \times 10 \mathrm{~mm})$. The ground material was extracted with distilled water ( $1 \mathrm{~h}, 3$ times) and $80 \%$ of ethanol ( $1 \mathrm{~h}, 3$ times) with ultrasonication. The cell walls were dried and finely ball-milled using a PULVERISETTE 7 (Fritsch, IdarOberstein, Germany) at $600 \mathrm{rpm}$ with $\mathrm{ZrO}_{2}$ vessels $(50 \mathrm{~mL})$ containing with $\mathrm{ZrO}_{2}$ ball bearings $(10 \times$ $10 \mathrm{~mm})$. Each sample $(200 \mathrm{mg})$ was milled for $1 \mathrm{~h}$ and $40 \mathrm{~min}$ in $10 \mathrm{~min}$ intervals with $5 \mathrm{~min}$ interval breaks to avoid excessive heating. The ball-milled sample $(50 \mathrm{mg}$ of each) was transferred into a $5-\mathrm{mm}$ NMR tube and the gel formed using DMSO- $d_{6} /$ pyridine- $d_{5}$ $(4: 1, v / v, 0.5 \mathrm{~mL})$ with sonication $(30 \mathrm{~min})$.

NMR spectra were acquired on a Bruker BioSpin (Billerica, MA, USA) AVANCE $700 \mathrm{MHz}$ spectrometer equipped with a cryogenically cooled $5-\mathrm{mm}$ triple-resonance ${ }^{1} \mathrm{H} /{ }^{13} \mathrm{C} /{ }^{15} \mathrm{~N}$ TXI gradient probe with inverse geometry $\left({ }^{1} \mathrm{H}\right.$ coils closest to the sample). The central DMSO solvent peak was used as internal reference $\left(\delta_{\mathrm{C}}\right.$ $\left.39.5, \delta_{\mathrm{H}} 2.49 \mathrm{ppm}\right)$. The ${ }^{1} \mathrm{H}-{ }^{13} \mathrm{C}$ correlation experiment was an adiabatic HSQC experiment (Bruker standard pulse sequence "hsqcetgpsisp.2"; phase-sensitive gradient-edited 2D HSQC using adiabatic pulses for inversion and refocusing) [24]. HSQC experiments were carried out using the following parameters: acquired from 9 to $1 \mathrm{ppm}$ in $\mathrm{F} 2\left({ }^{1} \mathrm{H}\right)$ with 1200 data points (acquisition time $200 \mathrm{~ms}), 160$ to $10 \mathrm{ppm}$ in $\mathrm{F} 1\left({ }^{13} \mathrm{C}\right)$ with 512 increments ( $\mathrm{F} 1$ acquisition time $13.6 \mathrm{~ms}$ ) of 32 scans with a 1 -s interscan delay; the $\mathrm{d}_{24}$ delay was set to $0.86 \mathrm{~ms}(1 / 8 \mathrm{~J}, \mathrm{~J}=145 \mathrm{~Hz})$. Volume integration of contours in HSQC plots used Bruker's TopSpin 3.1 (Mac) software. Assignments of peaks from NMR spectra were based on those in previous publications $[23,25]$. 
Table 1 FTIR band assignments for the corn stover substrates

\begin{tabular}{lllll}
\hline$\#$ & Wavenumber $\left[\mathrm{cm}^{-1}\right]$ & Assignment & Polymer & Reference \\
\hline 1 & $836-841$ & C-H out-of-plane in position 2 and 6 of S and in all positions G units & Lignin & Cellulose \\
2 & 898 & C-H deformation & Cellulose, hemicellulose, and lignin & {$[16]$} \\
3 & $1039-1043$ & C-O stretching & Lignin & {$[21]$} \\
4 & 1124 & Aromatic skeletal vibration and C-O stretching & Lignin & Lignin \\
5 & $1248-1256$ & C-O vibration of G rings & Lignin \\
6 & $1319-1323$ & C-O vibration of S rings & Lignin \\
7 & 1421 & Aromatic skeletal vibrations combined with C-H in-plane deformation & Lignin \\
8 & 1456 & C-H deformation & Lignin \\
9 & $1514-1517$ & Aromatic skeletal vibration & Xylan \\
10 & $1607-1608$ & Aromatic skeletal vibration & Lignin \\
11 & 1742 & C=O stretching in unconjugated ketone, carbonyl, and ester groups & Lignin \\
12 & 2806 & C-H stretching & Cellulose, hemicellulose, and lignin & {$[15]$} \\
13 & 2929 & C-H stretching in methyl and methylene groups & {$[16]$} \\
14 & 3328 & O-H stretching & {$[14,22]$} \\
\hline
\end{tabular}

Ammonia-extracted lignin from the SAA pretreatment was also analyzed by NMR. After the pretreatment, lignin-rich black liquor was collected and dried at $45{ }^{\circ} \mathrm{C}$ using a rotary evaporator (Rotavapor ${ }^{\circledR}$ R-215, BÜCHI, Labortechnik, Switzerland). Solid residues remaining in the flask were hydrolyzed by mixed enzymes of cellulase (Novozyme NS-50013, 70 FPU/mL) and xylanase (Novozyme NS-50030, 500 FXU (Farvet xylan unit)/mL) to purify the lignin. The purified insoluble lignin was filtered and air-dried. Acid-induced precipitation by adding $\mathrm{HCl}$ was also conducted to recover soluble lignin from the filtrate. The lignin was air-dried and mixed before the NMR analysis and subjected to lignin and carbohydrate analysis following the NREL-LAP [13].

\section{Gel-Permeation Chromatography}

The weight-average molecular weight $\left(M_{w}\right)$ and numberaverage molecular weight $\left(M_{n}\right)$ of ammonia-extracted lignin were estimated by gel-permeation chromatography (GPC) on a 1260 infinity HPLC system (Agilent Technology, Santa Clara, CA, USA) with a refractive index detector (RIG1362A) and a multiple wavelength detector (MWD). Three columns were connected in series including PLgel mixed B, PLgel mixed E $5 \mu \mathrm{m}$ with a pore size of $10,000 \AA$, and PLgel mixed E $5 \mu \mathrm{m}$ with a pore size of $100 \AA$ (Agilent, Santa Clara, CA). A set of polystyrene standards was used for calibration. Ammonia-extracted lignin was purified by the aforementioned enzymatic hydrolysis method and then acetylated in pyridine/acetic anhydride $(1: 1 \mathrm{v} / \mathrm{v})$ prior to GPC analysis to improve the solubility in tetrahydrofuran (THF) and minimize molecular association issues. Lignin $(10 \mathrm{mg})$ was suspended in $2 \mathrm{~mL}$ pyridine/acetic anhydride mixture and kept in the dark for $72 \mathrm{~h}$. The mixture was poured into cold water $(48 \mathrm{~mL})$ and stirred for $1 \mathrm{~h}$. The precipitate was collected and washed with water and ethyl ether and then dried in a freeze dryer. The purified and acetylated lignin $(2 \mathrm{mg})$ was dissolved in $1 \mathrm{~mL}$ THF and filtered using a syringe filter. The lignin solution $(10 \mu \mathrm{L})$ was injected onto the GPC columns with an eluent (THF) flow rate of $1.0 \mathrm{~mL} / \mathrm{min}$ at $25^{\circ} \mathrm{C}$. All data were processed using the Agilent ChemStation software package for GPC analysis (Rev.B.04.03).

\section{Results and Discussion}

\section{Effect of Ammonia Pretreatments on the Chemical Composition of Corn Stover}

The SAA pretreatment was able to effectively delignify corn stover under mild reaction conditions [26]. More than $50 \%$ of lignin in corn stover was removed in $6 \mathrm{~h}$ and about $70 \%$ of lignin was extracted in $12 \mathrm{~h}$ by $15 \%$ aqueous ammonia (Fig. 1a). Most of the glucan ( $>97 \%$ ) and xylan $(80 \%)$ in the corn stover remained in the pretreated biomass. The results suggested that the SAA has high selectivity toward the removal of lignin over polysaccharides. Selective delignification improved the accessibility of cellulose to enzymes, enriched carbohydrates in the pretreated corn stover, and presumably minimized enzyme inactivation by lignin absorption, which facilitated the high carbohydrate loading/concentration operations in the following hydrolysis and fermentation steps. As the reaction time was extended, more lignin was removed; however, more carbohydrates were solubilized as well. In particular, reaction times longer than $12 \mathrm{~h}$ could not notably remove more lignin but dissolved more xylan from the biomass.

The LMAA pretreatment method was introduced with the intention of reducing ammonia and water consumption [11]. The effect of LMAA reaction time on the composition of 

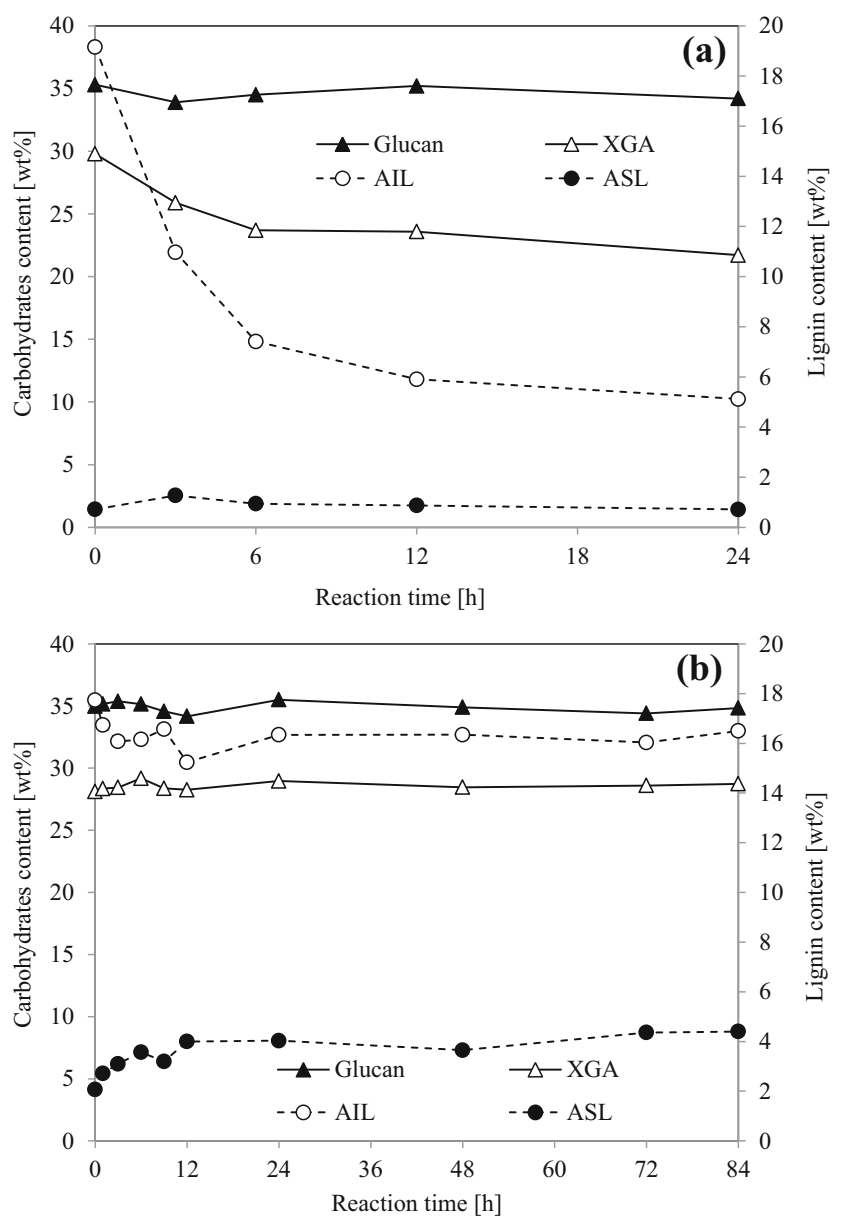

Fig. 1 Changes of carbohydrates (cellulose and hemicelluloses) and lignin content in the ammonia-pretreated solids, a SAA pretreatment and b LMAA pretreatment. $X G A$ the sum of xylan, galactan, and arabinan; AIL acid-insoluble lignin; $A S L$ acid-soluble lignin

biomass is presented in Fig. 1b. There was no significant change in the carbohydrate fractions during the LMAA pretreatment, whereas the ASL and AIL changed with the pretreatment. The ammoniation step itself slightly increased the ASL fraction (from 0.7 to $2.1 \%$ in Table 2), and the fraction was further increased up to $4.4 \%$ (accounting for $21.6 \%$ of overall lignin) as the pretreatment time increased. ASL is the fraction of lignin with relatively low molecular weight lignin fragments, as determined from the lignin analysis. Therefore, the results suggested that the LMAA pretreatment is able to modify and/or partially depolymerize lignin and form more ASL, even though there was no mass loss from the biomass during the pretreatment. The increase in the ASL fraction indirectly establishes the modification and cleavage of the lignin polymer in the LMAA pretreatment.

\section{Enzymatic Digestibility of Ammonia-Pretreated Corn Stover}

The main purpose of pretreatment is to improve the enzymatic digestibility of lignocellulosic biomass. Enzymatic hydrolysis
Table 2 Composition of untreated and pretreated corn stover

Pretreatment method Composition [wt $\%$ ]

Glucan Xylan Galactan Arabinan AIL ASL

\begin{tabular}{lllllrl}
\hline Untreated & 35.3 & 23.9 & 1.9 & 4 & 19.2 & 0.7 \\
SAA & 35.2 & 19.4 & 1.2 & 3 & 5.9 & 0.9 \\
LMAA & 34.8 & 22.2 & 1.9 & 4.6 & 16.5 & 4.4 \\
\hline
\end{tabular}

Pretreatment conditions for the SAA: $60^{\circ} \mathrm{C}, 12 \mathrm{~h}$, solid-to-liquid ratio= 1:10 $(w / v)$; for the LMAA: $80{ }^{\circ} \mathrm{C}, 72 \mathrm{~h}$. Data in the table are based on oven-dried untreated corn stover

$A I L$ acid-insoluble lignin, $A S L$ acid-soluble lignin

of the SAA- and LMAA-treated biomass was conducted to elucidate the efficiency of both the aqueous and gaseous ammonia pretreatments. Samples for the enzymatic hydrolysis tests were prepared under the selected conditions for high carbohydrates preservation, delignification, and degree of lignin decomposition in each pretreatment, i.e., $60^{\circ} \mathrm{C}$ and $12 \mathrm{~h}$ for SAA and $80^{\circ} \mathrm{C}$ and $72 \mathrm{~h}$ for LMAA.

The glucan and xylan digestibilities of pretreated and untreated corn stover are shown in Fig. 2. Avicel ${ }^{\circledR}$ PH101 (microcrystalline pure cellulose) was also hydrolyzed as a cellulose reference. In Fig. 2a, the glucan digestibility of both the SAA-treated and LMAA-treated biomass showed a rapid increase within the first $24 \mathrm{~h}$ and then slowly reached up to 90.7 and $84.2 \%$, respectively. Although the digestibility of the LMAA-treated biomass was slightly lower than that of the SAA-treated one, the result suggested that delignification is not prerequisite for effective enzymatic hydrolysis as the former (LMAA) kept almost all of lignin in the substrate. Xylan digestibility of both pretreated biomass samples showed a similar trend in Fig. 2b. Within $24 \mathrm{~h}$, more than $60 \%$ of xylan was hydrolyzed to xylose and reached to 84.9 and $74.8 \%$ at $96 \mathrm{~h}$ for the SAA-treated and LMAAtreated biomass, respectively. The overall recovery of xylose from the LMAA-treated biomass was higher as the LMAA-treated biomass retained most of its xylan, whereas the SAA-treated biomass lost $\sim 20 \%$ of its xylan during the pretreatment (Table 2 and Fig. 2). Nonetheless, both aqueous and gaseous ammonia pretreatments notably improved the glucan and xylan digestibility of pretreated biomass. Each pretreatment method has specific advantages and disadvantages. The SAA removed more lignin from biomass allowing more carbohydrates to become available in the following bioconversion steps at the same solid loading. However, a certain amount of carbohydrates, especially hemicelluloses, was "lost" during the process. The LMAA preserved all the carbohydrates, including glucan and XGA (xylan+galactan+ arabinan) and significantly reduced the ammonia 

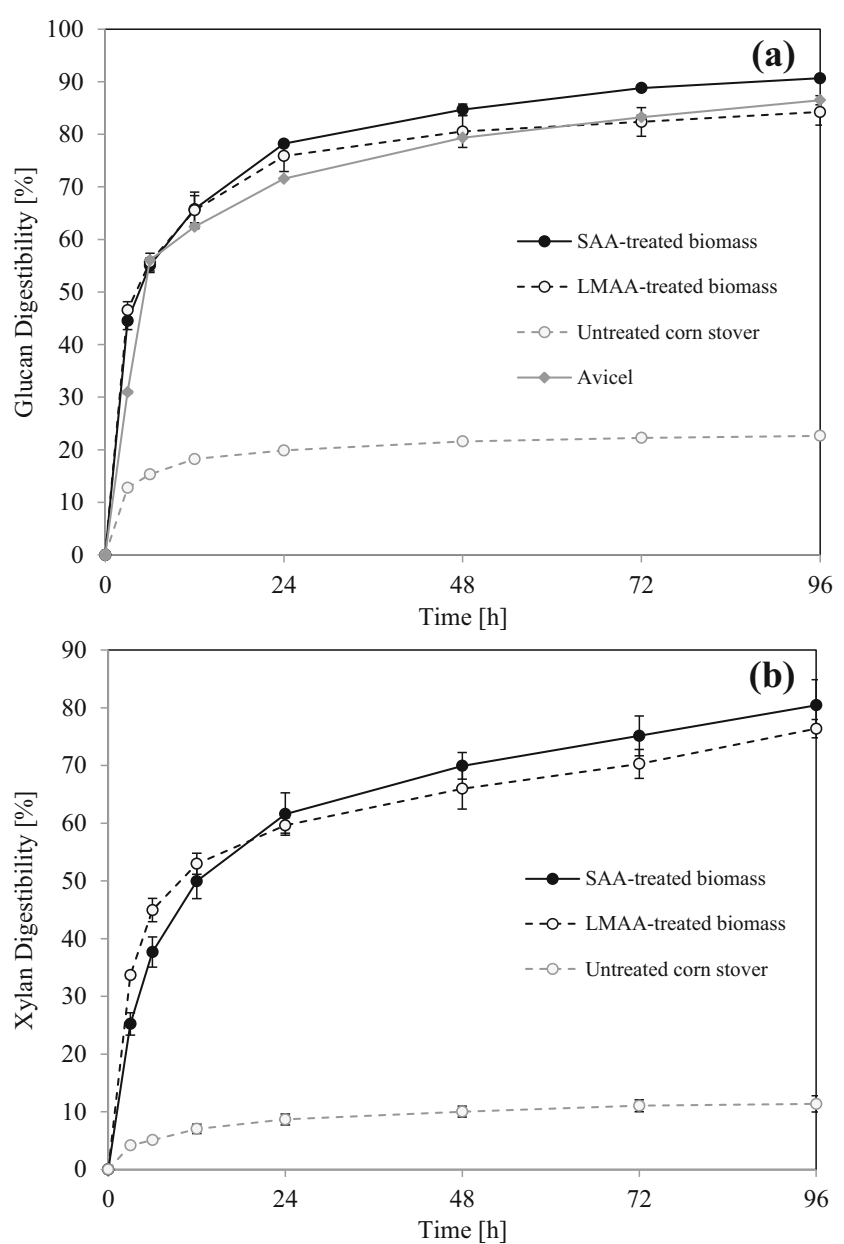

Fig. 2 Enzymatic digestibility of SAA and LMAA-treated biomass, a glucan digestibility and $\mathbf{b}$ xylan digestibility

consumption and water use because LMAA-pretreated biomass does not require washing before enzymatic hydrolysis. In summary, the overall carbohydrates available in LMAA-pretreated corn stover were higher than those in the SAA-treated biomass. However, glucan and xylan digestibility of the LMAA-treated biomass was lower than that of the SAA-treated alternative.

\section{Changes in Chemical Structure of Corn Stover After the Ammonia Pretreatments}

FTIR analysis was conducted to compare the structural changes in the biomass from the two ammonia pretreatments. As shown in the spectra (Fig. 3), the SAA-treated sample had lower bands for aromatic vibrations at 1607 and $1517 \mathrm{~cm}^{-1}$ and $\mathrm{C}-\mathrm{O}$ vibration from guaiacyl $(\mathrm{G})$ units, assigned to the band at $1248 \mathrm{~cm}^{-1}$, than untreated corn stover. The results support the contention above that SAA removed part of the lignin from the biomass. Also, a lower intensity $\mathrm{C}=\mathrm{O}$ stretching absorbance at $1742 \mathrm{~cm}^{-1}$ was found because of the removal of certain amounts of xylan from the biomass, and the likely cleavage of acetate, $p$-coumarate and ferulate esters from that fraction. The $\mathrm{O}-\mathrm{H}$ stretching peak from hydroxyl groups assigned at $3328 \mathrm{~cm}^{-1}$, the $\mathrm{C}-\mathrm{O}$ vibration of syringyl (S) rings of lignin at $1323 \mathrm{~cm}^{-1}$, the $\mathrm{C}-\mathrm{O}$ stretching at $1039 \mathrm{~cm}^{-1}$, and the $\mathrm{C}-\mathrm{H}$ deformation peak of cellulose at $898 \mathrm{~cm}^{-1}$ relatively increased after the SAA pretreatment. These observations are due to the delignification, which also resulted in an increase of the cellulose fraction in the pretreated biomass and in the relative fraction of S-type lignin by preferentially removing G-type lignin fractions (Fig. 4), as described later.

Compared to the SAA-treated sample, structural changes in the LMAA-treated sample were not as clearly evident. However, cleavage of lignin and hydroxycinnamate linkages by the LMAA pretreatment was established by the decreased bands related to lignin in FTIR spectra of the pretreated biomass. Specifically, the peaks of aromatic skeletal vibrations at 1608 and $1514 \mathrm{~cm}^{-1}$, the $\mathrm{C}-\mathrm{O}$ vibration related to $\mathrm{G}$ lignin at $1256 \mathrm{~cm}^{-1}$, and the $\mathrm{C}-\mathrm{H}$ out-of-plane vibration at $\mathrm{S}$ units at $841 \mathrm{~cm}^{-1}$ decreased after the LMAA pretreatment.

Two-dimensional (2D) ${ }^{1} \mathrm{H}_{-}{ }^{13} \mathrm{C}$ correlation (HSQC) NMR spectra, correlating protons with their attached carbons, profile the lignin structural changes after each pretreatment (Figs. 4, 5 , and 6). The overall differences can be recognized from the entire NMR data region from the cell wall and lignin components in Fig. 4, but the details are best seen in the assigned regions (see in the following sections). The LMAA-treated sample shows similar NMR correlations to that of the untreated corn stover (Fig. 4b), whereas the SAA-treated sample lost the lignin fraction almost completely during the pretreatment process (Fig. 4c), and the lignin signals were successfully recovered and examined in the SAA-extracted lignin (Fig. 4d).

Figures 5 and 6 allow the aromatic regions and aliphatic (side-chain and polysaccharide) regions of the NMR spectra to be more closely examined. In the side-chain and polysaccharide regions (Fig. 5), which represent the structural types and distribution of bonding patterns of the lignin fraction and the polysaccharides, it is evident that the LMAA-treated sample has similar cell wall components, including lignin, as the untreated control corn stover. However, the naturally occurring acetates on the xylan were completely removed as shown by the disappearance of the diagnostic 2-O- and 3-O-Ac- $\beta$-D-Xyl $p$ correlation contours. On the other hand, most of the lignin disappeared from the SAA-treated sample (Figs. $4 \mathrm{c}$ and $5 \mathrm{c}$, shown at lower contour level close to the noise level) in order to see the remaining residual aromatics. The lignin removed and recovered from the SAA-treated sample shows all of the essential lignin sidechain structures along with residual polysaccharides; these are sometimes considered to be lignin-polysaccharide complexes, but whether covalent bonds between the polymers are involved remains contentious. All three pretreated samples (Fig. 5b-d) also show severely decreased $\gamma$ - $p$-coumaroylated $\beta$-ether units 
Fig. 3 FTIR spectra of untreated and pretreated (SAA and LMAA) corn stover. Note: Peak numbers are described in Table 1

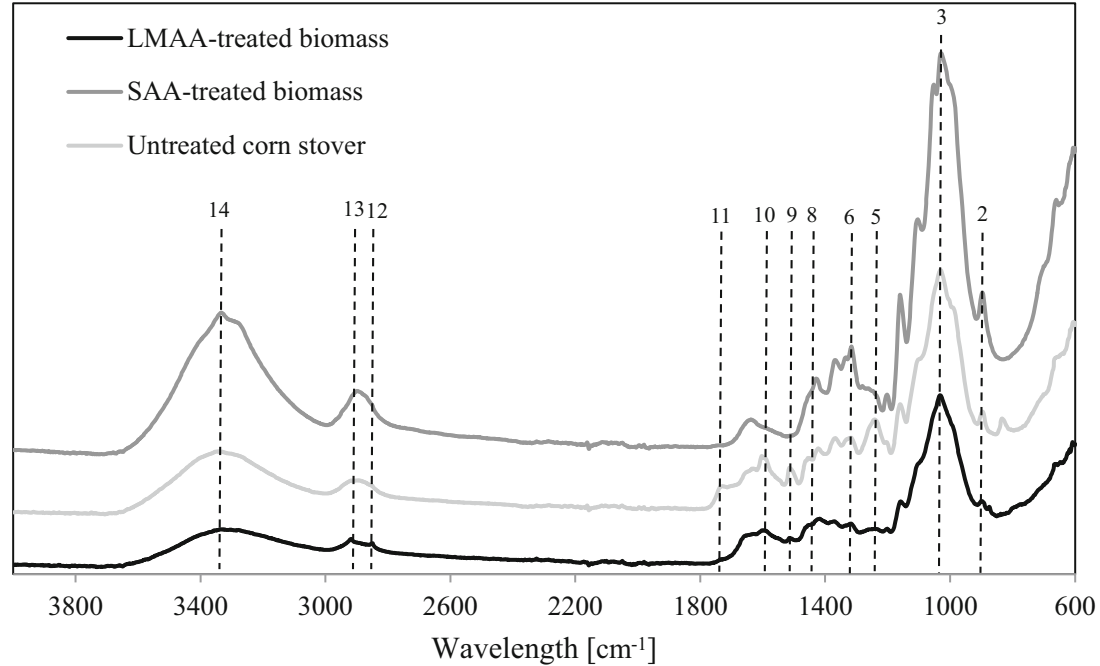

( $\beta$-O-4-S, peak labeled LA- $\mathrm{S}_{\gamma(\gamma-p \mathrm{CA})}$ ), again due to the cleavage of these primary esters by ammonia.

The aromatic regions show the distributions of $p$ hydroxyphenyl $(\mathrm{H})$, guaiacyl $(\mathrm{G})$, and syringyl (S) units of the lignin in the substrates, along with other aromatic components such as the hydroxycinnamates, ferulate (FA, acylating arabinoxylan), and $p$-coumarate ( $p \mathrm{CA})$, acylating both arabinoxylan and lignin [23, 25] (Fig. 6). In addition, benzylic-oxidized ( $\alpha$-ketone) structures of $S$ units were also detected in this region. As shown clearly in Fig. 4c, the SAA pretreatment significantly reduced or removed all of the lignin and hydroxycinnamate components from the biomass, and these components appeared in the isolated ammoniaextracted lignin. However, residual lignin remains evident at lower contour levels (closer to the noise level) (Fig. 6c). The G units were preferentially eliminated, but the $\mathrm{S}$ units and $p \mathrm{CA}$ were still visible in the biomass after the SAA pretreatment; incomplete cleavage of hydroxycinnamate esters by ammonia under these conditions is often observed. The major difference between the treated and the control samples is the appearance of amide structures shown in red. Although the amides are, in both cases, likely free-phenolic monomers, they remain in the ammoniaextracted lignin in part because of the way this sample is generated (as detailed in the "Materials and Methods" section); in particular, soluble components were precipitated with acid and combined with this fraction. In a prior study, the recalcitrance from the cell wall crosslinking mediated by ferulates in the corn stover and the effect of ammonia on cleaving ferulate ester bonds were reported [27]. The enhanced enzymatic hydrolysis that results from the biomass pretreatment and the structural

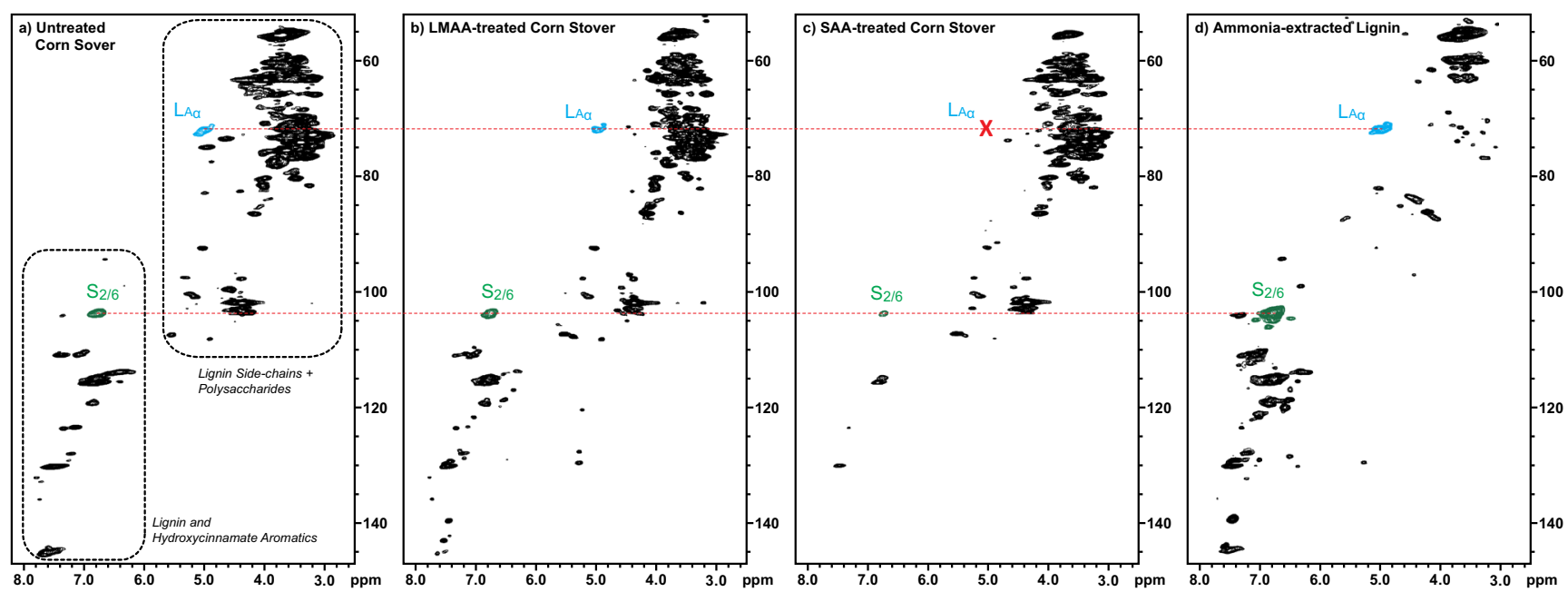

Fig. 4 Full regions of $2 \mathrm{D}^{1} \mathrm{H}_{-}{ }^{13} \mathrm{C}$ correlation (HSQC) $700 \mathrm{MHz}$ NMR spectra from cell wall gels and lignin in DMSO-d $\mathrm{d}_{6} /$ pyridine- $_{5}(4: 1)$. a Untreated corn stover, b LMAA-treated corn stover, $\mathbf{c}$ SAA-treated corn stover, d purified ammonia-extracted lignin (SAA pretreatment) 


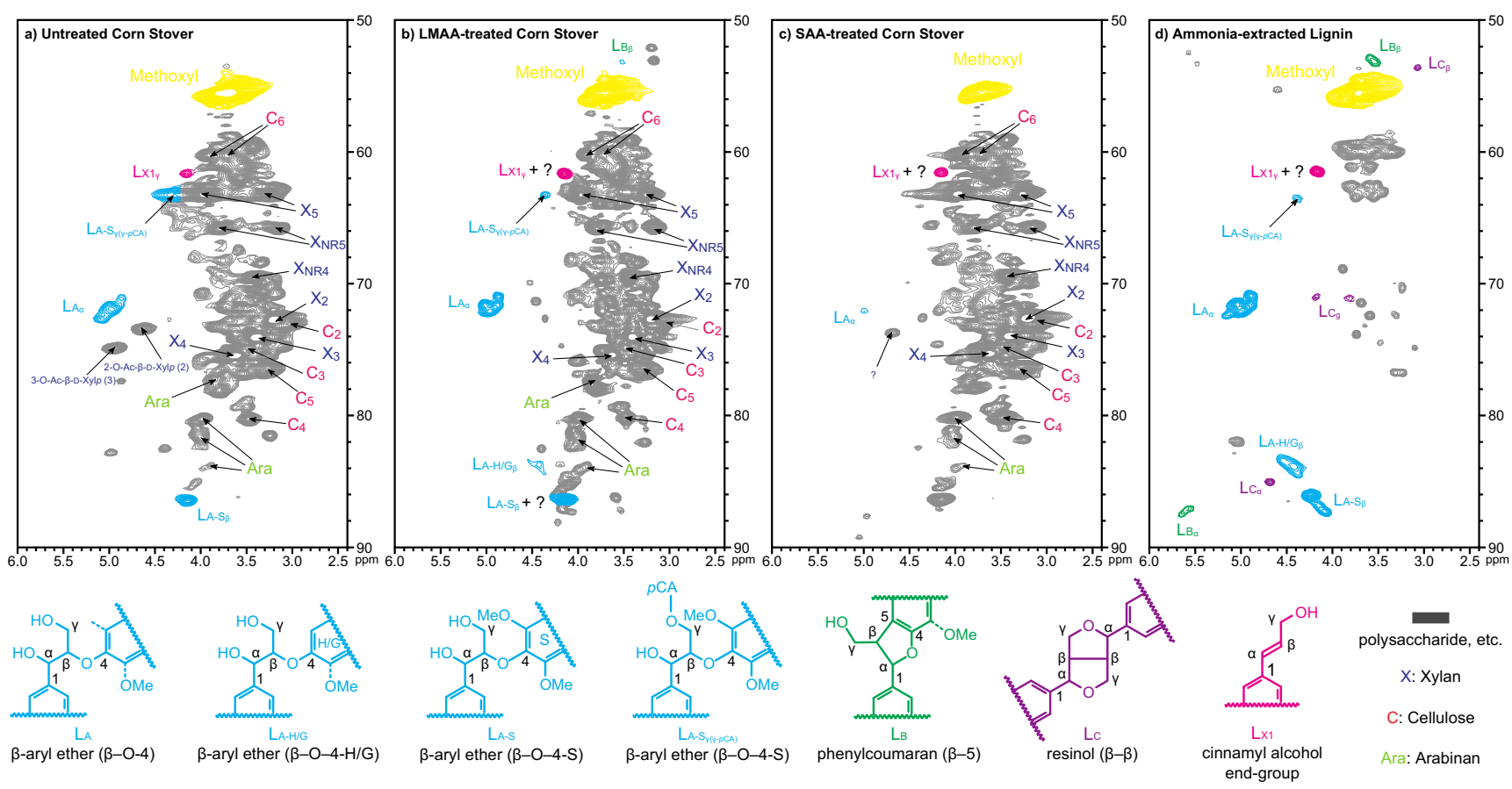

Fig. 5 Lignin side-chain (and polysaccharide) regions of $2 \mathrm{D}{ }^{1} \mathrm{H}-{ }^{13} \mathrm{C}$ correlation (HSQC) $700 \mathrm{MHz}$ NMR spectra from cell wall gels and lignin in DMSO- $\mathrm{d}_{6} /$ pyridine- $\mathrm{d}_{5}(4: 1)$. a Untreated corn stover, b LMAA-treated corn stover, c SAA-treated corn stover, d purified

changes of the SAA-treated and LMAA-treated samples, in particular, can be explained by the cleavage of ammonia-extracted lignin (SAA pretreatment) Note: Correlations from lignin side-chain components and polysaccharide correlations such as those from amorphous cellulose, $O$-acetylated xylan, and xylan are well isolated from the other heavily congested polysaccharide peaks

ferulate esters and their conversion to the amides and acids during the reaction (Figs. 2 and 6).
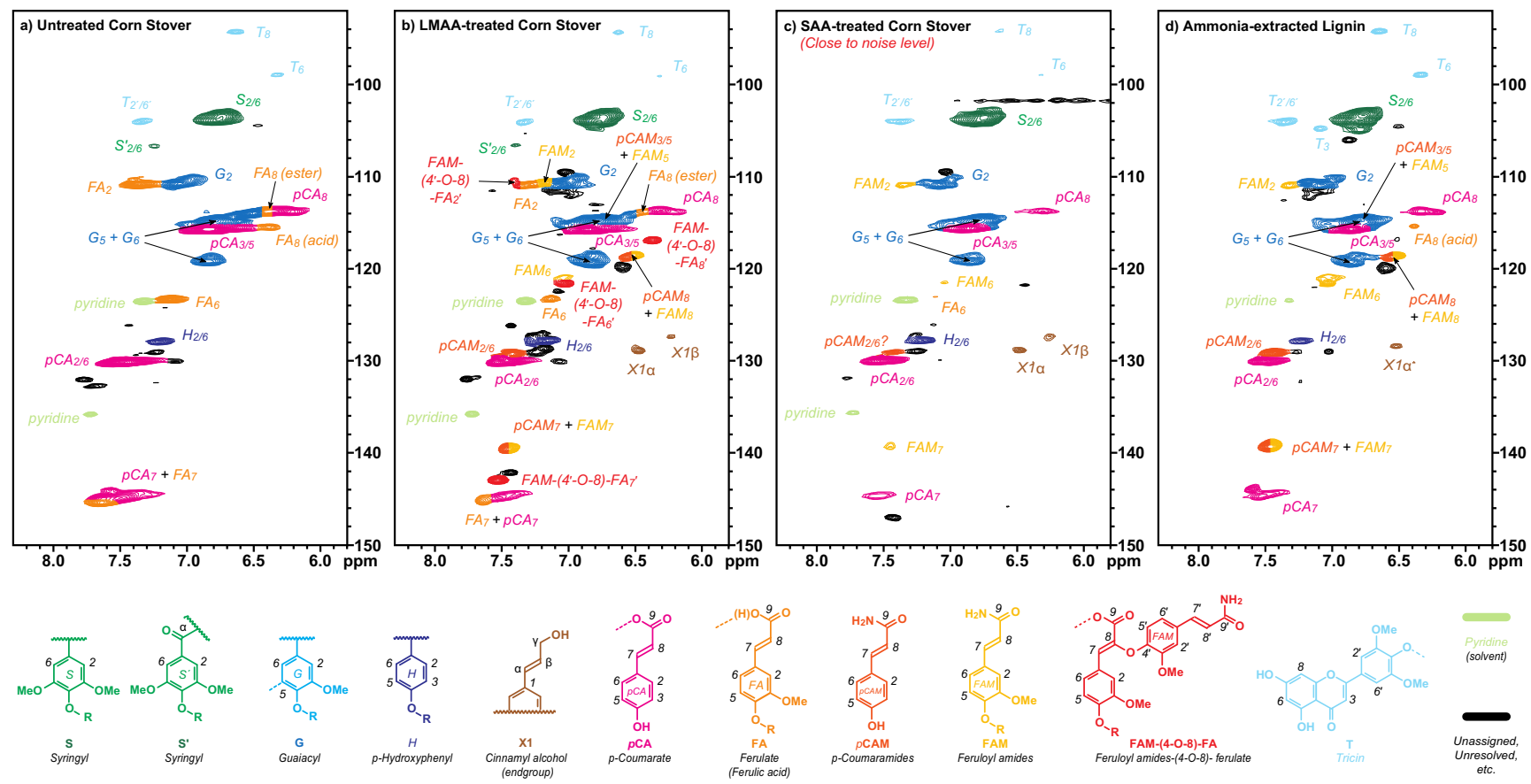

Fig. 6 Aromatic regions of $2 \mathrm{D}{ }^{1} \mathrm{H}^{-13} \mathrm{C}$ correlation (HSQC) $700 \mathrm{MHz}$ NMR spectra from cell wall gels and lignin in DMSO- $\mathrm{d}_{6} /$ pyridine- $_{5}$ (4:1). a Untreated corn stover, b LMAA-treated corn stover, c SAAtreated corn stover, d purified ammonia-extracted lignin (SAA pretreatment). Note: Correlations from the aromatic rings are well

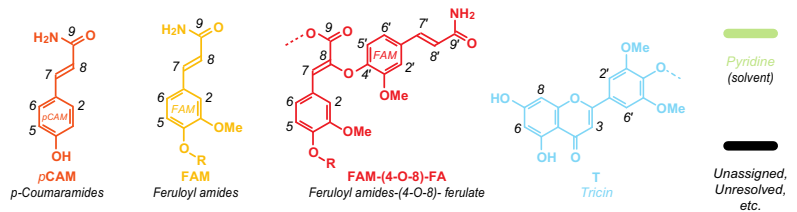

dispersed and can be characterized by the type of aromatic units (syringyl S, guaiacyl G, $p$-hydroxyphenyl $\mathrm{H}, p$-coumarate $p \mathrm{CA}$, ferulate FA, and amides AM). Note that the aromatics from SAA-treated corn stover were detected at near the base-plane noise level 


\section{Characteristics of Ammonia-Extracted Lignin in the SAA Pretreatment}

As discussed previously, the SAA pretreatment was able to moderately and selectively extract the lignin and hydroxycinnamates from biomass, generating an aromatic stream that has potential for co-product production. In this study, the ammonia-extracted lignin from the SAA pretreatment was therefore investigated. Although the SAA pretreatment was quite selective for lignin removal, the recovered lignin was still accompanied by low levels of carbohydrates, extractives, and other "impurities" (Fig. 4d). The lignin extracted in the SAA pretreatment at $60^{\circ} \mathrm{C}$ for $12 \mathrm{~h}$ was selected for characterization as the conditions resulted in significant delignification ( $70 \%$ ) with relatively low loss of hemicelluloses (xylan, galactan, and arabinan) ( 20\%) (Fig. 1a). Based on the lignin analysis, approximately $70 \%$ of the crude lignin recovered from the pretreatment liquor by evaporation was lignin, the remainder being hemicellulose-derived. The recovered part including crude lignin and other components was purified by hydrolyzing the hemicelluloses with enzymes. The purified lignin (purity $>98 \%$, based on lignin analysis) was characterized for functional groups, lignin structure, and molecular weight using FTIR, NMR, and GPC. The FTIR spectra of the ammonia-extracted lignin are shown in Fig. 7a. The bands for lignin, including the peaks of aromatic skeletal vibration at 1607,1517 , and $1421 \mathrm{~cm}^{-1}$, the $\mathrm{C}-\mathrm{H}$ deformation at $1456 \mathrm{~cm}^{-1}, \mathrm{G}$ unit assigned at $1248 \mathrm{~cm}^{-1}$, the $\mathrm{C}-\mathrm{H}$ out-of-plane vibration at $\mathrm{S}$ units at $836 \mathrm{~cm}^{-1}$, and the peak of aromatic skeletal and $\mathrm{C}-\mathrm{O}$ stretching at $1124 \mathrm{~cm}^{-1}$, are clearly observed, whereas the peak for the $\mathrm{C}-\mathrm{O}$ stretching at $1043 \mathrm{~cm}^{-1}$ is relatively small compared to that displayed for untreated corn stover. The aforementioned NMR spectra indicated that the lignin retained most of its normal lignin units during the pretreatment (Figs. 4, 5, and 6).

The molecular weight of the lignin provides information about the extent of its depolymerization. The THF-soluble lignin had a broad molecular weight distribution up to $25,000 \mathrm{~g} / \mathrm{mol}$. The weight-average molecular weight $\left(M_{w}\right)$ and number-average molecular weight $\left(M_{n}\right)$ of the purified ammonia-extracted lignin in THF were determined by GPC in triplicate (Table 3 and Fig. 7b) to be 3975 and $1827 \mathrm{~g} / \mathrm{mol}$, respectively, with a polydispersity index $\left(M_{w} / M_{n}\right)$ of 2.18 (Table 3).

\section{Conclusions}

This investigation elucidated the changes in chemical composition and structure and the disruption of linkages in the cell wall of corn stover brought about by the ammonia pretreatments. Approximately $70 \%$ of lignin was removed by the SAA, but the isolated lignin was remarkably "native like,"
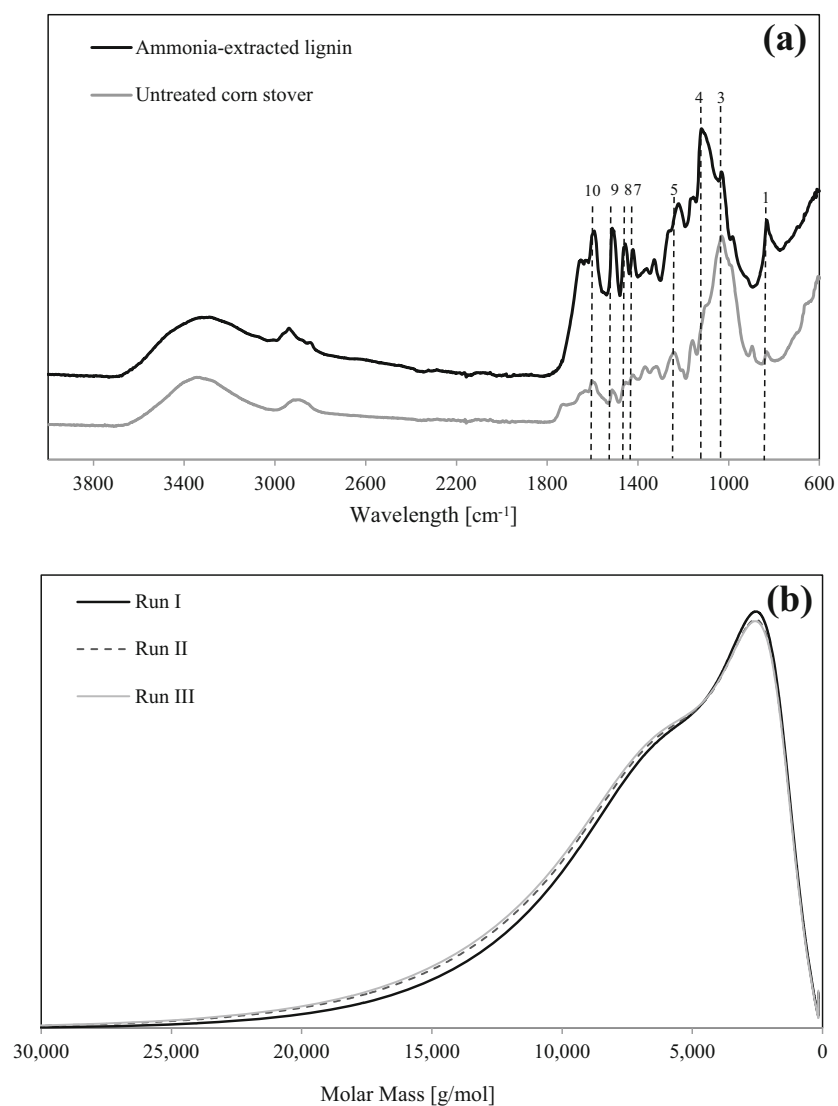

Fig. 7 Characterization of purified ammonia-extracted lignin in SAA pretreatment. a FTIR spectra of untreated corn stover and ammoniaextracted lignin. b Molecular weight distribution of ammonia-extracted lignin Note: Peak numbers are described in Table 1

possessing the major native linkages, and notably the $\beta$ ethers, of the structure intact. Most hydroxycinnamates were converted into hydroxycinnamamides (and possibly hydroxycinnamic acids) for both the SAA and LMAA pretreatments but a fraction survived intact. Although the LMAA method does not remove the lignin components from the cell wall polysaccharides, it is clear that the disruption of the crosslinking between cell wall components by cleavage the ferulates (linking arabinoxylan chains to each other and to lignin) and perhaps the conversion of ferulate and $p \mathrm{CA}$ esters to amides (and acids) improved the enzymatic hydrolysability of cell wall polysaccharides (glucan and xylan). Deacetylation of xylan is also expected to improve xylan hydrolysis if the

Table 3 Weight-average $\left(M_{w}\right)$ and number-average $\left(M_{n}\right)$ molecular weight $(\mathrm{g} / \mathrm{mol})$, and polydispersity $\left(M_{w} / M_{n}\right)$ of the ammonia-extracted lignin from the SAA pretreatment

\begin{tabular}{lllll}
\hline & Run I & Run II & Run III & Average \\
\hline$M_{w}$ & 3841 & 4013 & 4071 & 3975 \\
$M_{n}$ & 1789 & 1829 & 1862 & 1827 \\
$M_{w} / M_{n}$ & 2.15 & 2.19 & 2.19 & 2.18 \\
\hline
\end{tabular}


xylanases used are not able to cleave acetylated units [28]. Both pretreatments significantly improved the enzymatic hydrolysability of corn stover to the extent that 90 and $84 \%$ of glucan and 80 and $76 \%$ of xylan in the SAA-treated and LMAA-treated corn stover were hydrolyzed under the investigated conditions. Ammonia-extracted lignin recovered from the SAA pretreatment had low molecular weight and retained a high fraction of $\beta$-ether units, suggesting that the lignin would be a good feedstock for lignin-derived aromatic products.

Acknowledgments This work was supported by the R\&D program of MOTIE/KEIT (10049674). Chang Geun Yoo and Xuejun Pan were funded by NSF grant (CBET 1236562). Hoon Kim and John Ralph were funded by the DOE Great Lakes Bioenergy Research Center (DOE BER Office of Science DE-FC02-07ER64494). The authors also wish to thank Dr. Jijiao Zeng and Prof. Zhaohui Tong at the University of Florida for their GPC analysis.

\section{References}

1. Luque R, Herrero-Davila L, Campelo JM, Clark JH, Hidalgo JM, Luna D, Marinas JM, Romero AA (2008) Biofuels: a technological perspective. Energy Environ Sci 1(5):542-564

2. Bozell JJ (2008) Feedstocks for the future - biorefinery production of chemicals from renewable carbon. Clean-Soil, Air, Water 36(8): 641-647

3. Kim TH, Kim TH (2014) Overview of technical barriers and implementation of cellulosic ethanol in the U.S. Energy 66:13-19

4. Zhao X, Zhang L, Liu D (2012) Biomass recalcitrance. Part I: the chemical compositions and physical structures affecting the enzymatic hydrolysis of lignocellulose. Biofuels Bioprod Biorefin 6(4): 465-482

5. Agbor VB, Cicek N, Sparling R, Berlin A, Levin DB (2011) Biomass pretreatment: fundamentals toward application. Biotechnol Adv 29(6):675-685

6. Kim TH, Kim JS, Sunwoo C, Lee YY (2003) Pretreatment of corn stover by aqueous ammonia. Bioresour Technol 90(1):39-47

7. Kim TH, Lee YY (2005) Pretreatment of corn stover by soaking in aqueous ammonia. Appl Biochem Biotechnol 124(1-3):1119-1132

8. Mosier N, Wyman C, Dale B, Elander R, Lee YY, Holtzapple M, Ladisch M (2005) Features of promising technologies for pretreatment of lignocellulosic biomass. Bioresour Technol 96(6):673-686

9. Tajkarimi M, Riemann HP, Hajmeer MN, Gomez EL, Razavilar V, Cliver DO (2008) Ammonia disinfection of animal feeds-laboratory study. Int J Food Microbiol 122(1-2):23-28

10. Taylor F, Kim TH, Abbas CA, Hicks KB (2008) Liquefaction, saccharification, and fermentation of ammoniated corn to ethanol. Biotechnol Prog 24(6):1267-1271
11. Yoo CG, Nghiem NP, Hicks KB, Kim TH (2011) Pretreatment of corn stover using low-moisture anhydrous ammonia (LMAA) process. Bioresour Technol 102(21):10028-10034

12. Alizadeh H, Teymouri F, Gilbert TI, Dale BE (2005) Pretreatment of switchgrass by ammonia fibre explosion (AFEX). Appl Biochem Biotechnol 124(1-3):1133-1141

13. Sluiter A, Hames B, Ruiz R, Scarlata C, Sluiter J, Templeton D, Crocker D (2012) Determination of structural carbohydrates and lignin in biomass. National Renewable Energy Laboratory

14. Zhang J, Deng H, Lin L, Sun Y, Pan C, Liu S (2010) Isolation and characterization of wheat straw lignin with a formic acid process. Bioresour Technol 101(7):2311-2316

15. Sim SF, Mohamed M, Lu NALMI, Sarman NSP, Samsudin SNS (2012) Computer-assisted analysis of fourier transform infrared (FTIR) spectra for characterization of various treated and untreated agriculture biomass. BioResources 7(4):5367-5380

16. Shi J, Li J (2012) Metabolites and chemical group changes in the wood-forming tissue of Pinus Koraiensis under inclined conditions. BioResources 7(3):3463-3475

17. Rana R, Langenfeld-Heyser R, Finkeldey R, Polle A (2010) FTIR spectroscopy, chemical and histochemical characterisation of wood and lignin of five tropical timber wood species of the family of Dipterocarpaceae. Wood Sci Technol 44(2):225-242

18. Pandey KK, Pitman AJ (2003) FTIR studies of the changes in wood chemistry following decay by brown-rot and white-rot fungi. Int Biodeterior Biodegrad 52(3):151-160

19. Ferhan M, Yan N, Sain M (2013) A new method for demethylation of lignin from woody biomass using biophysical methods. J Chem Eng Process Technol 4(5):160

20. Mansouri N-EE, Yuan Q, Huang F (2011) Characterization of alkaline lignins for use in phenol-formaldehyde and epoxy resins. BioResources 6(3):2647-2662

21. Guo F, Shi W, Sun W, Li X, Wang F, Zhao J, Qu Y (2014) Differences in the adsorption of enzymes onto lignin from diverse type of lignocellulosic biomass and underlying mechanism. Biotechnol Biofuels 7(1):1-10

22. Sun Y-C, Xu J-K, Xu F, Sun R-C, Jones GL (2014) Dissolution, regeneration and characterisation of formic acid and Alcell lignin in ionic liquid-based systems. RSC Adv 4(6):2743-2755

23. Kim H, Ralph J, Akiyama T (2008) Solution-state 2D NMR of ballmilled plant cell wall gels in DMSO- $d_{6}$. Bioenergy Res 1(1):56-66

24. Kupče E, Freeman R (2007) Fast multidimensional NMR by polarization sharing. Magnetic resonance in chemistry. Magn Reson Chem 45(1):2-4

25. Kim H, Ralph J (2010) Solution-state 2D NMR of ball-milled plant cell wall gels in DMSO- $d_{6} /$ pyridine- $d_{5}$. Org Biomol Chem 8(3): 576-591

26. Kim TH, Taylor F, Hicks KB (2008) Bioethanol production from barley hull using SAA (soaking in aqueous ammonia) pretreatment. Bioresour Technol 99(13):5694-5702

27. Azarpira A, Lu F, Ralph J (2011) Reactions of dehydrodiferulates with ammonia. Org Biomol Chem 9(19):6779-6787

28. Drzewiecki K, Angelov A, Ballschmiter M, Tiefenbach KJ, Sterner R, Liebl W (2010) Hyperthermostable acetyl xylan esterase. Microb Biotechnol 3(1):84-92 